\title{
Phenotypic parameters predict time to normalization in infants with hypogammaglobulinemia.
}

\author{
Robert C. Van Winkle \\ Thomas Jefferson University \\ Walter W. Hauck \\ Sycamore Consulting, LLC \\ Stephen J. McGeady \\ Thomas Jefferson University
}

Follow this and additional works at: https://jdc.jefferson.edu/pedsfp

Part of the Pediatrics Commons

Let us know how access to this document benefits you

\section{Recommended Citation}

Van Winkle, Robert C.; Hauck, Walter W.; and McGeady, Stephen J., "Phenotypic parameters predict time to normalization in infants with hypogammaglobulinemia." (2013). Department of Pediatrics Faculty Papers. Paper 60.

https://jdc.jefferson.edu/pedsfp/60

This Article is brought to you for free and open access by the Jefferson Digital Commons. The Jefferson Digital Commons is a service of Thomas Jefferson University's Center for Teaching and Learning (CTL). The Commons is a showcase for Jefferson books and journals, peer-reviewed scholarly publications, unique historical collections from the University archives, and teaching tools. The Jefferson Digital Commons allows researchers and interested readers anywhere in the world to learn about and keep up to date with Jefferson scholarship. This article has been accepted for inclusion in Department of Pediatrics Faculty Papers by an authorized administrator of the Jefferson Digital Commons. For more information, please contact: JeffersonDigitalCommons@jefferson.edu. 


\title{
Phenotypic parameters predict time to normalization in infants with hypogammaglobulinemia.
}

\author{
Robert C. Van Winkle, MD. Thomas Jefferson University. Philadelphia, PA. \\ Walter W. Hauck, PhD. Sycamore Consulting, LLC. Philadelphia, PA. \\ Stephen J. McGeady, MD. The Nemours Foundation. Wilmington, DE.
}

\begin{abstract}
Infants with recurrent infection may be found to have hypogammaglobulinemia without impaired specific antibody responses. Many of these infants will eventually be diagnosed with transient hypogammaglobulimenia of infancy after hypogammaglobulinemia has resolved. This study used parametric survival analysis of 100 infants with hypogammaglobulinemia to evaluate parameters that predict time to normalization. Aggregate initial immunoglobulin levels $(\lg G+\lg A+\lg M)$, viewed as a percentage of age-adjusted normal values, predicted time to resolution of hypogammaglobulinemia: the median time to resolution for the infants in the lowest quartile of aggregate immunoglobulin levels ( $\leq 81 \%$ of age-adjusted lower limits of normal) was greater than five years with $34 \%$ resolving in 3 years. For infants in the highest quartile ( $\geq 130 \%$ of age-adjusted lower limits of normal) the median time to resolution was 9.9 months with $77 \%$ resolving in 3 years $(p=0.008)$. Initial IgG level, viewed as a percentage of age-adjusted normal values, also predicted time to resolution: the median time to resolution in the lowest quartile ( $\leq 78 \%$ of age-adjusted lower limits of normal) was greater than 5 years with $36 \%$ resolving in 3 years. For infants in the highest quartile $(\geq 128 \%)$ the median time to resolution was 14.5 months with $70 \%$ resolving in 3 years $(p=0.010)$. Male gender was also associated with more rapid resolution of hypogammaglobulinemia. The median time to resolution in males was 13 months with $73 \%$ resolving in 3 years. The median time to resolution in females was greater than 5 years, with $32 \%$ resolving in 3 years. These results suggest that if a term infant presents with hypogammaglobulinemia, protective specific antibody titers, and an absence of other known immune deficiency, initial immunoglobulin levels and gender may be used to predict time to normalization.
\end{abstract}

Keywords Hypogammaglobulinemia • immunoglobulins • immunity • infancy • primary immunodeficiency

\section{Introduction}

Infants with recurrent infection are often referred to allergists/immunologists because of concern about possible immune system dysfunction, and hypogammaglobulinemia, without impaired specific antibody responses, may be found. Such infants are usually considered to have transient hypogammaglobulinemia of infancy (THI). THI has been defined by the International Union of Immunological Societies (IUIS) as a transient delay reaching normal levels of IgG and IgA.[1] However, it has recently been shown that infants with an isolated decrease in IgA are clinically similar to infants with decreased IgG and IgA.[2] THI has been associated with increased production of TNF-alpha, TNF-beta and IL-10.[3] A report in 1981 associated THI with numerical and functional deficiency of helper T-cells 
[4]; more recently, however, THI has been associated with a transient increase in numbers of regulatory T-cells.[5]

Complicating the assessment and prognostication about infants with hypogammaglobulinemia is the reality that a diagnosis of THI can only be established in retrospect, after immunoglobulin levels have normalized.[6] Without question, some Infants with hypogammaglobulinemia will not have resolution of their deficiency and those infants with persistent hypogammaglobulinemia may be at increased risk for recurrent infection and autoimmune disease.[7] At the time of initial recognition of hypogammaglobulinemia in an infant, since this may be physiologic, immunologists are often finding with clinically relevant questions regarding the likely duration of hypogammaglobulinemia. Previous studies have shown that males are more likely than females to have resolution of hypogammaglobulinemia during infancy,[8] however, other than this observation, there has been little information that would allow an informed prediction about the probable time to resolution to hypogammaglobulinemia. The goal of this study was to define parameters, present at the time of diagnosis that might predict time to resolution of hypogammaglobulinemia.

\section{Methods}

Subjects Between 1978-2011, 100 infants with hypogammaglobulinemia were identified during routine clinical evaluation in the Division of Allergy, Asthma and Clinical Immunology at A.I. duPont Hospital for Children (Wilmington, DE) and Thomas Jefferson University (Philadelphia, PA). Infants were included in the study if they had an IgG and/or IgA level that was below the $5^{\text {th }}$ percentile of the ageadjusted mean, were less than 24 months old at the time of diagnosis, were born at greater than 36 weeks gestation, had evidence of protective diphtheria \& tetanus titers following immunization, and had no other known primary immune deficiency. Infants were excluded from the study if they were born prematurely (i.e. 37 weeks gestation), if diphtheria \& tetanus antibody titers post immunization were not protective, or if there was another known primary immune deficiency. The institutional IRB reviewed the protocol and waived the requirement for parental informed consent.

Statistics Infants were grouped into quartiles, on the basis of the sum of initial $\lg G+\lg A+\lg M$, viewed as a percentage of the lower limit of age-appropriate normal values. (See figure 1.) In a separate analysis, infants were grouped into quartiles on the basis of the initial IgG, viewed as a percentage of the lower limit of age-appropriate normal values. (See figure 2.) And in a final analysis, infants were grouped using gender since earlier evaluations described gender difference. Groups were compared with one another regarding time to resolution using interval censored data and parametric survival analysis (SAS version 9.1.3). Interval censored data was used because an actual date of normalization is not known; only an interval during which a patient's immunoglobulin levels normalized. Prior studies checked the reasonableness of this model by Kaplan-Meier curves, using interval midpoints as time to normalization, and found very similar results when compared to model-based graphs.[8] Quartiles were compared with one another regarding age at diagnosis and percentage male using Kruskal-Wallis and Chi-square methods, respectively. 


\section{Results}

In this total cohort, the median age at diagnosis was 11.3 months and $71 \%$ of the subjects were male. Initial immunoglobulin determination was obtained most frequently because of recurrent otitis media and upper respiratory tract infection (67\%), recurrent lower respiratory tract infection (24\%) or failure to thrive (14\%). (See Table I.)

There was no statistically significant difference in age at diagnosis or percentage male when the study population was divided into quartiles on the basis of initial aggregate immunoglobulin isotypes as a percentage of normal. (See Table II.) There was a statistically significant association of quartile of aggregate immunoglobulin isotypes as percentile of age-adjusted lower limit of normal and time to resolution $(p=0.008)$. The median time to resolution for the infants in the lowest quartile of immunoglobulins ( $\leq 81 \%$ of age-adjusted lower limits of normal) was greater than five years with only $34 \%$ resolving in 3 years. For infants in the highest quartile $(\geq 130 \%$ of age-adjusted lower limits of normal) the median time to resolution was 9.9 months with $77 \%$ resolving in 3 years. Results for the other two quartiles are intermediate, but not significantly different in those for the highest quartile. (See figure 1.)

There was also no statistically significant difference in age at diagnosis and percentage male when the study population was divided into quartiles on the basis of initial IgG alone as percentage of normal. (See Table III.) There was a statistically significant association of quartile of isolated IgG percentile age-adjusted lower limit of normal and time to resolution $(p=0.010)$. The median time to resolution in the lowest quartile ( $\leq 78 \%$ of age-adjusted lower limits of normal) was greater than 5 years with $36 \%$ resolving in 3 years. For infants in the highest quartile ( $\geq 128 \%)$ the median time to resolution was 14.5 months with $70 \%$ resolving in 3 years. (See figure 2.)

In agreement with previously reported findings,[8] male infants resolved more quickly than females $(p=0.001)$. The median time to resolution in males was 13 months with $73 \%$ resolving in 3 years. The median time to resolution in females was greater than 5 years, with $32 \%$ resolving in 3 years.

\section{Discussion}

Although many presenting infants with hypogammaglobulinemia will have early resolution of their decreased immunoglobulin levels, thereby leading to a diagnosis of THI, a subset have significantly delayed normalization or receive alternative diagnoses. It is important to discriminate between infants who are likely to have early resolution of hypogammaglobulinemia and infants who are likely to have persistence because there is evidence that infants with prolonged unresolved hypogammaglobulinemia are more likely to have recurrent infection and autoimmune problems.[7]

This study confirms an easily understood hypothesis: infants with mild or moderate decreases in initial aggregate immunoglobulin levels or IgG levels alone are more likely to outgrow their immunologic deficiency and to do so sooner when compared to infants with greater decreases in 
immunoglobulin levels. Not surprisingly, infants with higher initial aggregate immunoglobulin levels have a greater probability of prompt resolution. A major contribution of this study is that immunoglobulin levels have been delineated, using the concept of percentage normal for age, that allow a clinician to estimate the probability of resolution for hypogammaglobulinemia in infants without evidence of another primary immune deficiency by a particular age. At the time of initial evaluation, immunologists may use aggregate immunoglobulin levels or initial IgG levels to predict probability of resolution, although the aggregate immunoglobulin level does so with greater power. Although other markers such as cytokine measurements[3] or regulatory T-cell measurements, [5] have been associated with resolution of hypogammaglobulinemia, these markers are not readily available outside of a research setting and are therefore of little use to most clinicians. Aggregate immunoglobulin as a percentage of minimal normal and IgG as a percentage of minimal normal can be easily calculated by a practicing clinician and may be of significant practical utility.

As shown in previous studies, male gender was also associated with more prompt resolution of hypogammaglobulinemia. It is unclear why hypogammaglobulinemic male infants tend to resolve their initial hypogammaglobulinemia more rapidly than female infants, but the finding has been noted in two prior studies involving 49 and 87 infants respectively (8) (2). It is also notable that the male gender was overrepresented in our study population, with males composing $71 \%$ of our patients. Other studies of infants with hypogammaglobulinemia have also had similarly disproportionate numbers of male infants.[9, 10] It is possible that studies defining "normal" immunoglobulin levels by age may not accurately reflect naturally occurring differences in immunoglobulin levels due to gender or racial differences, thereby predisposing male infants to being mistakenly diagnosed with hypogammaglobulinemia. Further studies are needed to define the normal immunoglobulin maturation patterns between males and females.

\section{Conclusions}

These results suggest that if a term infant presents with hypogammaglobulinemia, protective specific antibody titers, and an absence of other known immune deficiency, an immunologist may use the sum of initial IgG + IgA + IgM to predict time to normalization. Furthermore, the initial IgG level also allows estimation of time to resolution. And, male gender was associated with more prompt resolution of symptoms. Further study is warranted to elucidate regarding possible long-term sequelae of hypogammaglobulinemia during infancy and the pathophysiologic mechanisms that underlie hypogammaglobulinemia during infancy.

\section{Acknowledgements}

The authors would like to thank Christopher C. Chang for his ideas regarding established normal values of immunoglobulins. 
Fig. 1 Calculation used for initial grouping of subjects

$$
\frac{\operatorname{Infant}(\operatorname{Ig} G+\operatorname{Ig} A+\operatorname{Ig} M)}{\text { Lower limit of normal }(\operatorname{Ig} G+\operatorname{Ig} A+\operatorname{Ig} M)} \times 100
$$

Fig. 2 Calculation used for secondary grouping of subjects

$$
\frac{\text { Inf ant IgG }}{\text { Lower limit of normal IgG }} \times 100
$$

Table I Reasons immunoglobulins were initially obtained

\begin{tabular}{|l|l|}
\hline Upper respiratory tract infections & $67 \%$ \\
\hline Lower respiratory tract infections & $24 \%$ \\
\hline Failure to thrive/GI complaints & $14 \%$ \\
\hline Skin infections & $4 \%$ \\
\hline Recurrent fevers & $3 \%$ \\
\hline Hematologic abnormalities & $2 \%$ \\
\hline CNS infections & $1 \%$ \\
\hline
\end{tabular}

Table II Descriptive statistics, based on initial aggregate (IgG + $\lg A+\lg M)$ immunoglobulin percentage

\begin{tabular}{|c|c|c|c|c|c|}
\hline & $\begin{array}{l}1^{\text {st }} \\
\text { quartile }\end{array}$ & $\begin{array}{l}2^{\text {nd }} \\
\text { quartile }\end{array}$ & $\begin{array}{l}3^{\text {rd }} \\
\text { quartile }\end{array}$ & $\begin{array}{l}4^{\text {th }} \\
\text { quartile }\end{array}$ & $\begin{array}{l}P \text { - } \\
\text { value }\end{array}$ \\
\hline $\mathrm{N}$ & 25 & 25 & 25 & 25 & \\
\hline $\begin{array}{l}\text { Range of immunoglobulin } \\
\text { levels, viewed as a } \\
\text { percent of normal }\end{array}$ & $\leq 81 \%$ & $\begin{array}{l}82- \\
104 \%\end{array}$ & $\begin{array}{l}105- \\
129 \%\end{array}$ & $\geq 130 \%$ & \\
\hline$\%$ male & 71 & 72 & 60 & 80 & 0.54 \\
\hline $\begin{array}{l}\text { Median age at diagnosis } \\
\text { (months) }\end{array}$ & 11 & 10 & 11 & 13 & 0.28 \\
\hline
\end{tabular}
normal quartile

Table III Descriptive statistics, based on initial IgG immune "oglobulin percentage normal quartile 


\begin{tabular}{|l|l|l|l|l|l|}
\hline & $\begin{array}{l}\mathbf{1}^{\text {st }} \\
\text { quartile }\end{array}$ & $\begin{array}{l}\mathbf{2}^{\text {nd }} \\
\text { quartile }\end{array}$ & $\begin{array}{l}\mathbf{3}^{\text {rd }} \\
\text { quartile }\end{array}$ & $\begin{array}{l}\mathbf{4}^{\text {th }} \\
\text { quartile }\end{array}$ & $\begin{array}{l}\mathbf{P} \text { - } \\
\text { value }\end{array}$ \\
\hline $\mathrm{N}$ & 25 & 25 & 26 & 24 & \\
\hline $\begin{array}{l}\text { Range of immunoglobulin } \\
\text { levels, viewed as a } \\
\text { percent of normal }\end{array}$ & $\leq 78 \%$ & $\begin{array}{l}79- \\
100 \%\end{array}$ & $\begin{array}{l}101- \\
127 \%\end{array}$ & $\geq 128$ & \\
\hline$\%$ male & 76 & 60 & 77 & 71 & 0.533 \\
\hline $\begin{array}{l}\text { Median age at diagnosis } \\
\text { (months) }\end{array}$ & 10 & 11 & 11 & 13 & 0.839 \\
\hline
\end{tabular}

Fig. 3 Probability of resolution in relationship to sum aggregate immunoglobulin percentage (IgG + IgA + IgM) of age-adjusted normal

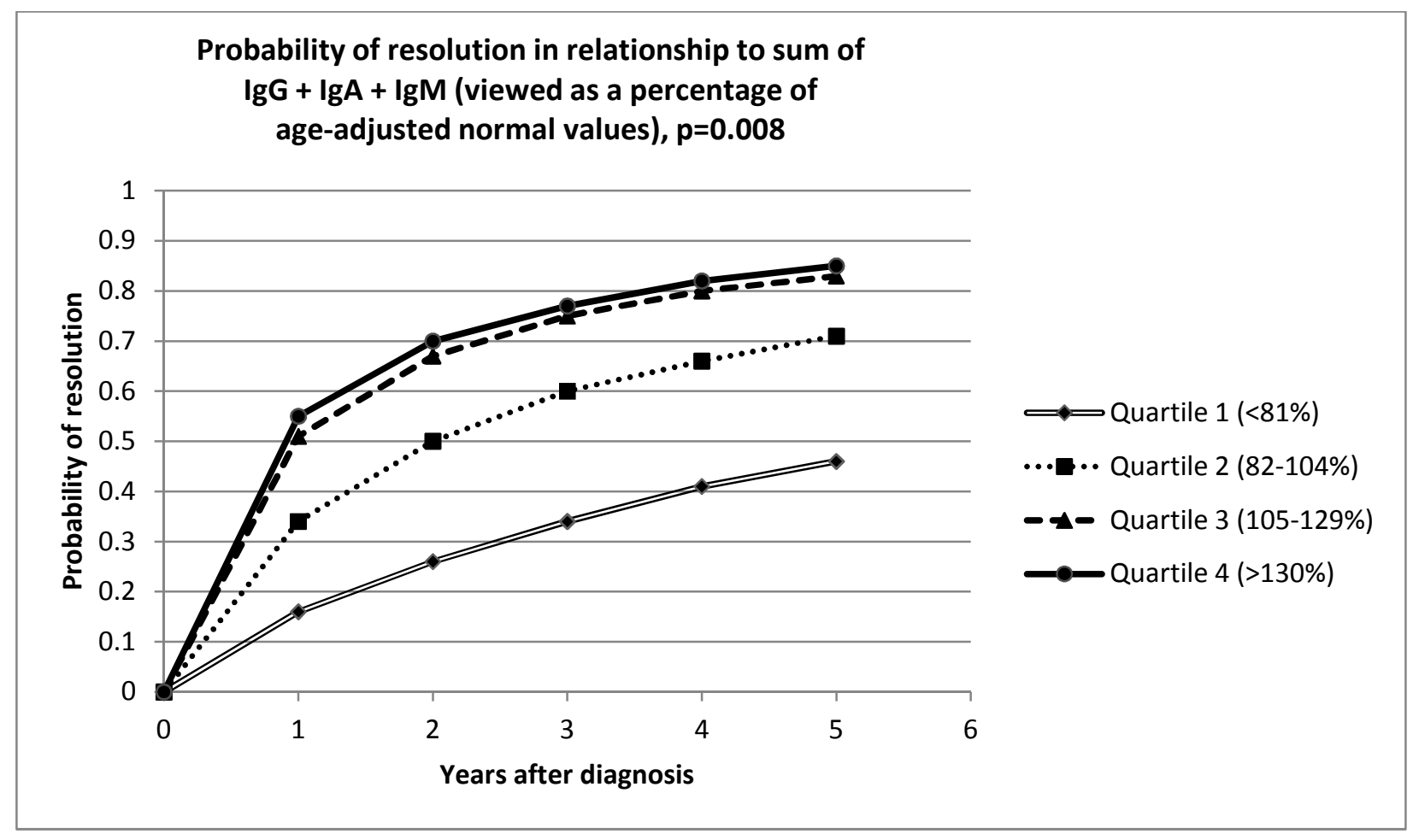

Fig. 4 Probability of resolution in relationship IgG percentage of age-adjusted normal 


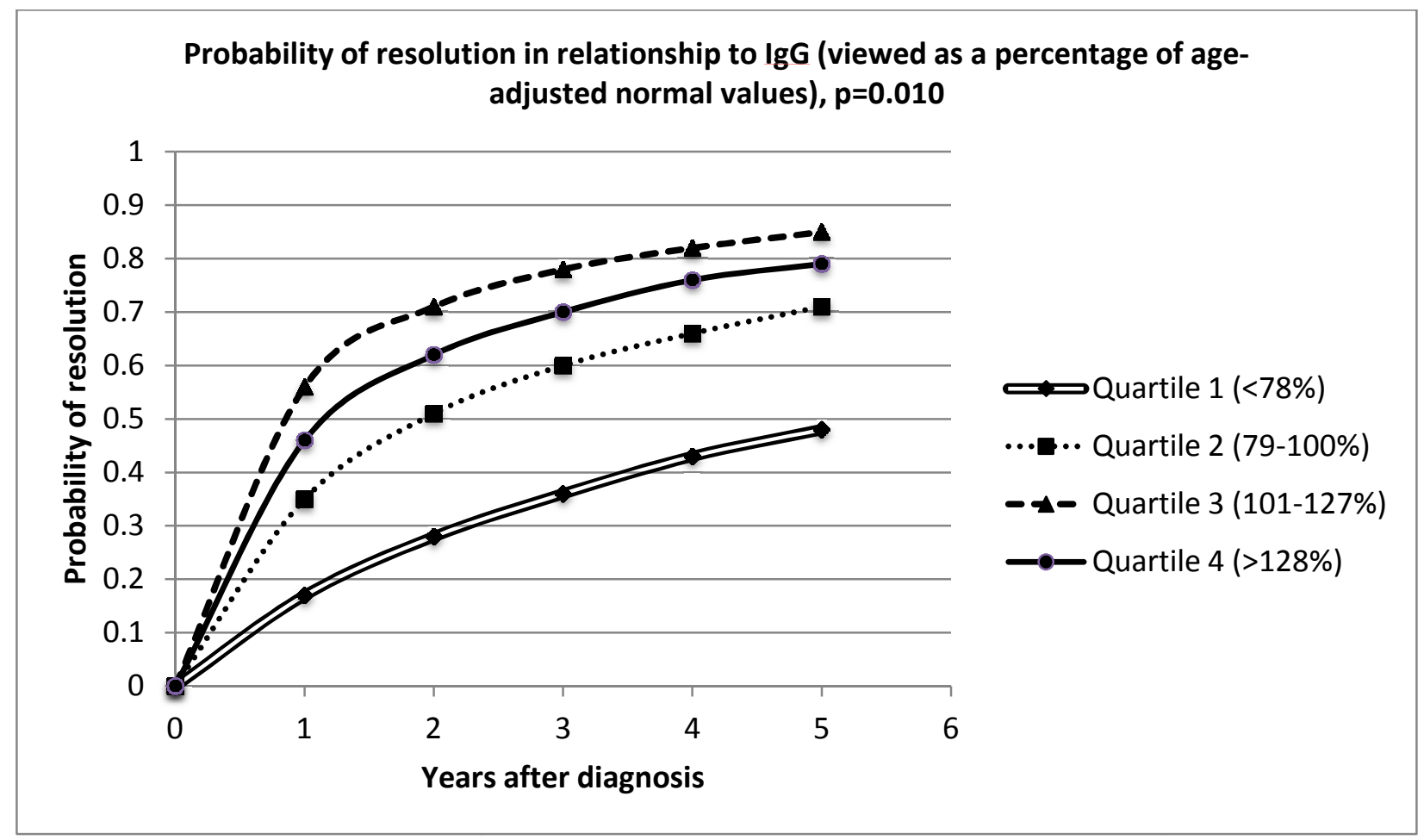

Fig. 5 Probability of resolution in relationship to gender

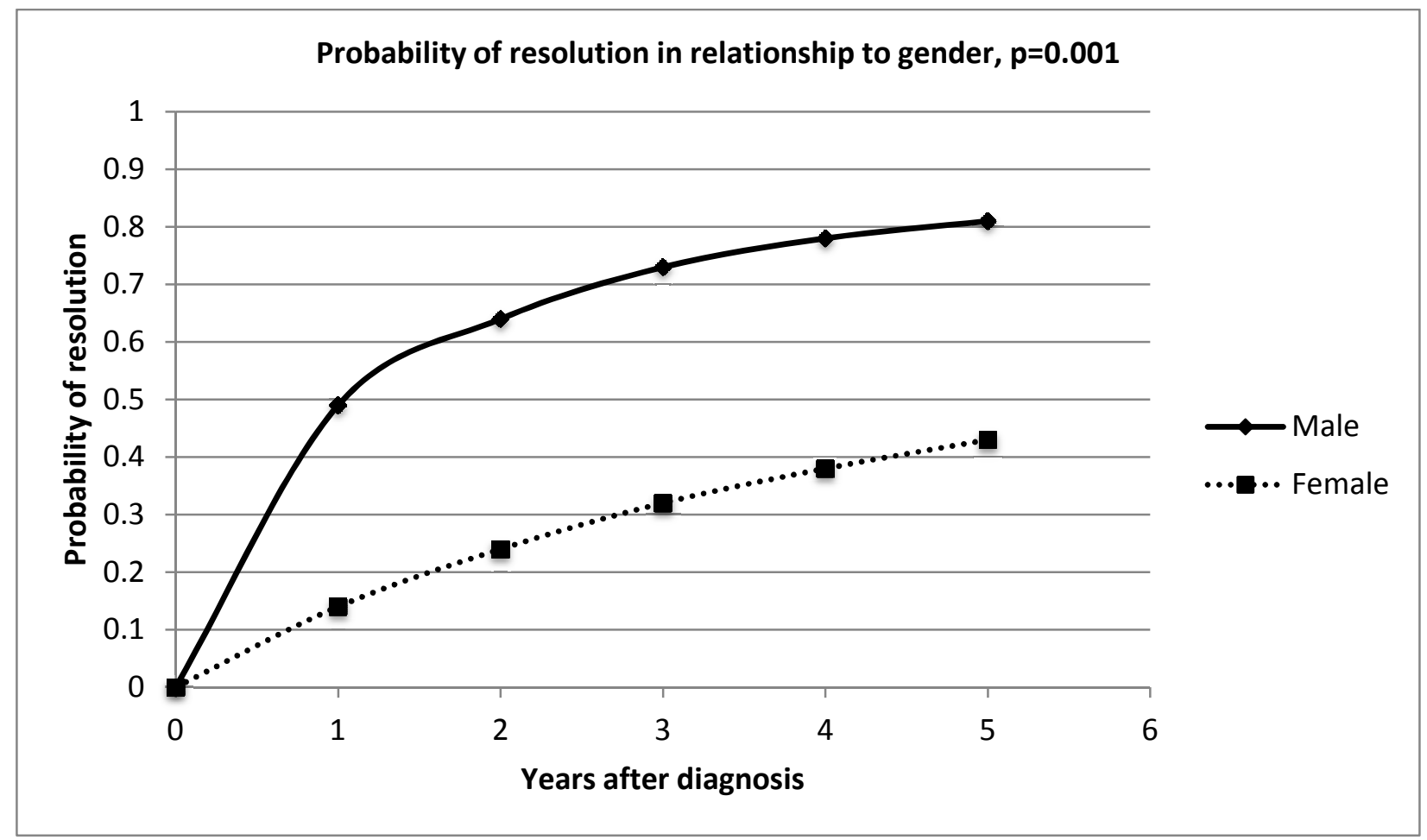


1. Notarangelo, L., et al., Primary immunodeficiency diseases: an update from the International Union of Immunological Societies Primary Immunodeficiency Diseases Classification Committee Meeting in Budapest, 2005. J Allergy Clin Immunol, 2006. 117(4): p. 883-96.

2. Horwitz, A., S.J. Kung, and S.J. McGeady, Infants with low immunoglobulin levels: Isolated low IgA level vs other immunoglobulin abnormalities. Ann Allergy Asthma Immunol, 2010. 105(4): p. 295-8.

3. Kowalczyk, D., et al., Intracellular cytokine production by Th1/Th2 lymphocytes and monocytes of children with symptomatic transient hypogammaglobulinaemia of infancy (THI) and selective IgA deficiency (SIgAD). Clin Exp Immunol, 2002. 127(3): p. 507-12.

4. Siegel, R.L., et al., Deficiency of T helper cells in transient hypogammaglobulinemia of infancy. N Engl J Med, 1981. 305(22): p. 1307-13.

5. Rutkowska, M., et al., The number of circulating CD4+CD25high Foxp + T lymphocytes is transiently elevated in the early childhood of transient hypogammaglobulinemia of infancy patients. Clin Immunol, 2011. 140(3): p. 307-10.

6. McGeady, S.J., Transient hypogammaglobulinemia of infancy: need to reconsider name and definition. J Pediatr, 1987. 110(1): p. 47-50.

7. Moschese, V., et al., A prospective study on children with initial diagnosis of transient hypogammaglobulinemia of infancy: results from the Italian Primary Immunodeficiency Network. Int J Immunopathol Pharmacol, 2008. 21(2): p. 343-52.

8. Whelan, M.A., et al., Infants presenting with recurrent infections and low immunoglobulins: characteristics and analysis of normalization. J Clin Immunol, 2006. 26(1): p. 7-11.

9. Keles, S., et al., Transient hypogammaglobulinemia and unclassified hypogammaglobulinemia: 'similarities and differences'. Pediatr Allergy Immunol, 2010. 21(5): p. 843-51.

10. Qian, J.H., et al., Clinical features and follow-up of Chinese patients with symptomatic hypogammaglobulinemia in infancy. Chin Med J (Engl), 2009. 122(16): p. 1877-83. 